\title{
Competitive consumption: A profusion of pie, pizza and pulled pork
}

$\mathrm{O}$ ne morning in 2007, Peter Czerwinski and several friends visited a breakfast pub. He was feeling particularly hungry, so he ordered a dish called "The Linebacker," which contained two of every breakfast item on the menu. After wolfing it down, he noticed his friends were only a quarter of the way through their plates. And he was still hungry. Also, he was curious: How many Linebackers could a person eat in one sitting?

"The record was two plates in an hour. I did four," says Czerwinski, who at the time was studying mechanical engineering at McMaster University in Hamilton, Ontario.

Realizing he had an uncommon capacity to consume food, Czerwinski went in search of other gustatory challenges. He shattered restaurant records. He competed in online eating contests. After eating a 72-ounce steak (sirloin, medium rare) in six minutes and 48 seconds, setting a new world record, he drew the attention of the competitive eating circuit in the United States and was invited to put his mouth up against some stiffer competition.

Now 27 years old, Czerwinski has been a professional eater since 2008, winning contest after contest and earning a living through sponsorships, prizes, YouTube videos and television appearances. He has consumed a profusion of pie and pizza and pulled pork, a mountain of meatballs, a cornucopia of cabbage and curry and chicken wings, a barge of burgers, a superfluity of sandwiches and sausages, a deluge of dumplings and a wagonload of watermelons and waffles. He's guzzled a bottle of olive oil, downed a pound of butter and survived the Trinidad Moruga Scorpio (the world's hottest pepper).

In short, Czerwinski, known as "Furious Pete," is an extreme eater.

It should come as no surprise that many doctors, nutritionists and dietitians aren't big fans of extreme feats of

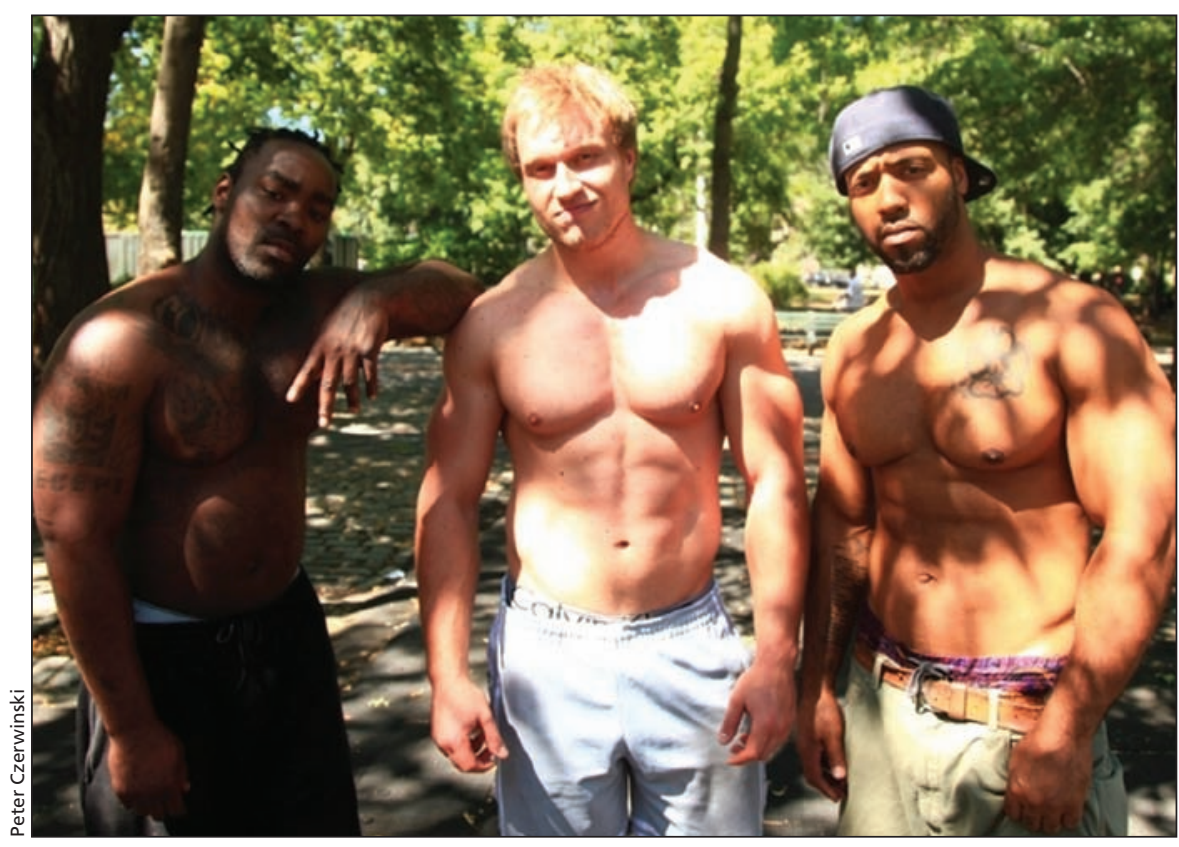

Peter Czerwinski (centre), a world-class competitive eater, and friends stay in shape through weight training and eating healthy outside of speed-eating events.

competitive consumption. After all, a contestant in a hot dog-eating contest ingests more calories in 10 minutes than a typical person consumes in 10 days, not to mention all the sodium, fat and cholesterol. Some people have even called for the sport of competitive eating to be banned in their jurisdictions, claiming it glorifies gluttony - not exactly a positive message for nations such as Canada and the United States, which are struggling with epidemic levels of obesity.

Yet there is no body of evidence to indicate either the short- or long-term effects of extreme eating. Many of the top eaters in the world are actually quite fit, including Czerwinski, a bodybuilder who is 104 kilograms of solid muscle. Japanese legend Takeru "The Tsunami" Kobayashi - a victor of the Glutton Bowl who has eaten 83 vegetarian jiaozi dumplings in eight minutes, 58 bratwurst sausages in $10 \mathrm{~min}$ utes and 337 chicken wings in a half hour — weighs a mere 58 kilograms.
It is reasonable, of course, to speculate about the risks of any extreme behaviour, but it might be more productive to explore how competitive eaters are able to ingest such large volumes of food. A greater understanding of that could prove helpful in aiding those who are polar opposites, gastronomically speaking, of competitive eaters - people with dyspepsia, a common condition characterized by discomfort after eating modest portions of food.

"Maybe we can do something for these people by looking at the people on the other end of the spectrum," says Dr. David Metz, a professor of medicine at the University of Pennsylvania in Philadelphia, who contributed to a study of competitive eating ( $A m J$ Roentgenol 2007;189:681-6).

"We know of no studies on the short- or long-term effects of speed eating on its competitors," states the study. "Nor are there any data in the literature about the science of speed eating and how its competitors are able to con- 
sume such enormous quantities of food in such short periods of time."

In the study, a world-class eater and a control subject were asked to eat as many hot dogs (without buns) as possible. Both ingested barium and were placed on a fluoroscopy table, in a semiupright position, to allow the capture of x-ray images of their stomachs in real time. The control subject ate seven hot dogs before stopping. The competitive eater ate 36 hot dogs in 10 minutes and still didn't feel bloated or full, only stopping at the insistence of the researchers, who observed his massively distended abdomen and worried he would suffer a gastric perforation.

There are several theories about how people such as Czerwinski are able to eat so much, so quickly. It has been attributed to factors such as a strong jaw, extreme mental focus, high pain tolerance and a deadened gag reflex. Some competitors seem able to com- pletely relax all the muscles in their esophagus, creating a hollow tube, in effect, that can be crammed with food.

But it is the unusual stomachs of gustatory athletes that seem to hold the most potential for helping people with dyspepsia. A normal stomach is around the size of two fists and can hold 2-4 litres of food. When someone eats, the brain informs the muscles in the stomach to relax to accommodate the food. The stomach contracts when full, pushing food into the intestine, and sends a signal of discomfort to the brain to stop the consumption. In people with dyspepsia, this signal is sent prematurely. In competitive eaters, on the other hand, the signal is delayed. Or perhaps it isn't sent at all.

"People usually feel full after 20 minutes," says Czerwinski. "I never really get that sensation."

In Metz's study, the stomach of the competitive eater was described as an "enormous flaccid sac." Some competi- tors increase the capacity of their stomachs through training, such as chugging gallons of water. This can be dangerous, though, posing risks such as water intoxication, a potentially deadly dilution of electrolytes in the body. Then there are people like Czerwinski, who don't need to train.

"Part of it is natural, being born with a big stomach and the ability to fill it up, to relax and expand it," says Metz.

A better understanding of the ability of a competitive eater to consume such large quantities of food without experiencing pain, however that comes about, may be the key to helping those for whom eating regular-sized meals are discomforting experiences, suggests Metz. "Our hope is that for people with dyspepsia, we could potentially train them to take bigger volumes of food." - Roger Collier, CMAJ

CMAJ 2013. DOI:10.1503/cmaj.109-4394

\section{Competitive consumption: Ten minutes. 20000 calories. Long-term trouble?}

$\mathrm{I}$ $\mathrm{t}$ all started, according to legend, as an argument between four immigrants about who loved their adopted homeland the most. The heated discussion took place in 1916 at Nathan's Famous, a hot dog stand that had recently opened on Coney Island in New York City. The establishment's owner, Nathan Handwerker, feared fisticuffs might ensue, so he proposed a contest.

Whoever could eat the most hot dogs in 12 minutes would be declared the most patriotic of the bunch. James Mullen, a native of Ireland, claimed the title by downing 13 hot dogs, buns included. That contest continues to this day. Held annually on July 4, it is considered the top dog of all eating competitions, with US\$10 000 going to the champ.

Do today's winners eat more than 13 hot dogs? Ah, yeah, a few more. Let's just say masticating a baker's dozen of sodium-rich beef tubes isn't much to brag about anymore. Reigning six-time champion Joey Chestnut took Nathan's coveted Mustard Belt in 2012 by laying waste to a record-tying 68 hot dogs in
10 minutes. Mullen had eaten just over one hot dog per minute. Chestnut ate one every nine seconds.

The annual contest at Nathan's Famous is but one of dozens of events sanctioned by Major League Eating, the franchise behind the professional competitive eating circuit. Other competitions include Ben's Chilli Bowl's World Chilli Eating Championship (total cash purse: US\$3000), Western Days Festival World Tamale Eating Championship (total cash purse: US\$3500) and the Oktoberfest Zinzinnati World BratwurstEating Championship (total cash purse: US\$2000).

If an item is edible, there is probably somebody somewhere eating a whole lot of them in hopes of winning a prize.

Reactions to the rise in popularity of the "sport" of extreme eating generally fall into two categories. There are those who marvel at the ability of these rubber-bellied gurgitators to wolf down (and keep down) mountains of food. The Nathan's Famous contest draws about 40000 spectators and is broadcast inter- nationally on ESPN. Then there are those who find the whole affair grotesque. Celebrating overconsumption in a nation suffering an obesity epidemic, they argue, is just plain wrong, and competitive eaters are setting themselves up for a lifetime of health problems.

But are participants in speed-eating contests really putting their health at risk? And if so, to what extent?

"The bottom line is, there is such minimal data that we are doing a lot of conjecture," says Dr. David Metz, professor of medicine at the University of Pennsylvania in Philadelphia, who contributed to a study of competitive eating (Am J Roentgenol 2007;189:681-6).

That said, physicians do know enough about how the human body works to take some educated guesses about the possible effects of repeatedly bingeing on massive quantities of food. According to the study, these risks include gastroparesis (slowing of food movement out of the stomach), intractable nausea, vomiting, gastric perforation, Mallory-Weiss tear (tear in 